\title{
Machine components clustering with DSM and repeating method : case study of a soil mixing machine
}

\author{
Tanongsak Kongsin* and Sakon Klongboonjit \\ Industrial Engineering Department, Faculty of Engineering, King Mongkut's Institute of Technology Ladkrabang, Bangkok, Thailand
}

\begin{abstract}
In this study, components of the machine are analyzed to group all components into modular groups with a case study of a soil mixing machine. The study begins by creating a design structure matrix of all components. Next, the design structure matrix is transferred into a distance matrix of all components with Jaccard method. After that, the equation of complete linkage must be applied to change the distance matrix to a tree dendrogram for showing the relationship of machine components and dependent coefficient. With this tree dendrogram, six clusters are arranged:- the $1^{\text {st }}$ cluster has 8 modules at the lowest dependent coefficient, the $2^{\text {nd }}$ cluster has 7 modules, the $3^{\text {rd }}$ cluster has 6 modules, the $4^{\text {th }}$ cluster has 5 modules, the $5^{\text {th }}$ cluster has 4 modules, and the $6^{\text {th }}$ cluster has 2 modules at the highest dependent coefficient. Finally, the $1^{\text {st }}$ cluster with 8 modules is considered to be the most proper cluster for this soil mixing machine by applying the repeating method to analyze all six clusters.
\end{abstract}

\section{Introduction}

Modular design has continuously been developed with a base on multi-resolution modeling to serve with a flexible manufacturing system (FMS). With FMS, machines in production processes must easily change machine functions in response to unstable marketing demand without buying new machines. To design changeable machines, Design Structure Matrix (DSM) should be applied to design a process of the machine to develop new generation machine which consists of many modules and this type of machine can change its function by changing its modules. Many research studies of the DSM show decomposition and integration analysis whether the system is a product or a process. [1] They include the designs assembly system layout for mass customization. [2] This approach could assist selecting model resolution more flexibility, based on needs or understanding degree for the complex system [3].

In this paper, an application of DSM with Jaccard Method and repeating method is introduced to be a new idea to design a modular machine [4] that can easily change its function, its components and maintenance.

\section{Purpose}

The main purpose of this study is to apply the clustering with DSM and repeating method for modular design of the soil mixing machine [10]. The main expected result is to group machine components into independent modules for easily developing new generation machine, disassembling its components, and setting a maintenance plan.

\section{Study Methodology}

In this study, Design Structure Matrix (DSM) and Repeating Method are applied for clustering machine components into independent modules [5]. To obtain the expected results, the study processes consist of 5 steps as shown in Fig. 1.

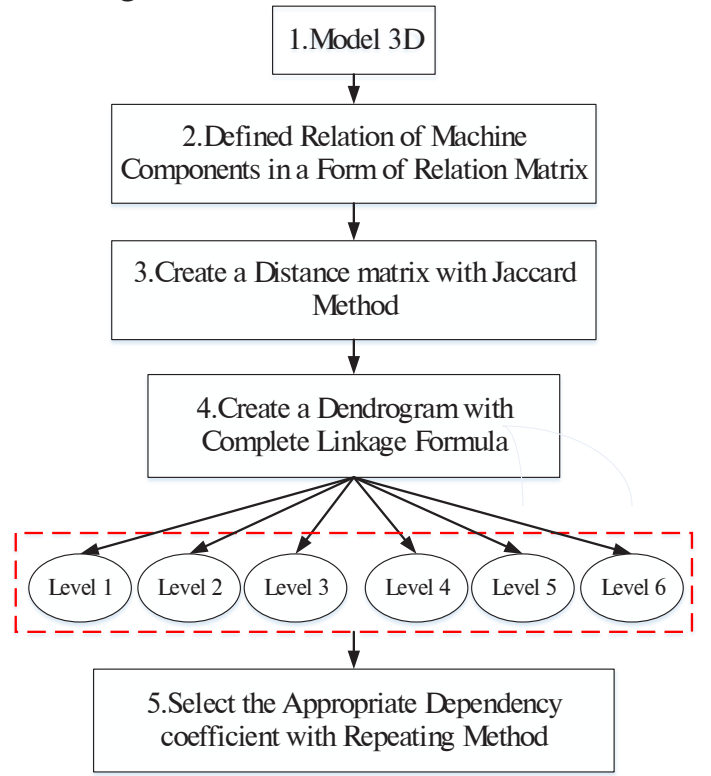

Fig. 1. The Clustering flow diagram.

\footnotetext{
* Corresponding author: tanongsak9797@gmail.com, sklonboonjit@hotmail.com
} 


\section{Results}

\subsection{Model 3D}

The soil mixing machine is designed by CAD software to create model 3D of this machine as shown in Fig. 2.

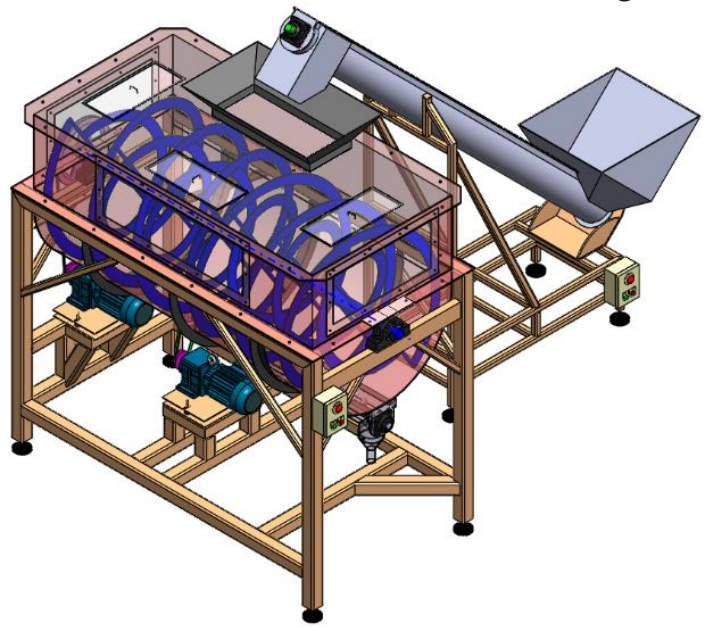

Fig. 2. 3D model for soil mixing machine

\subsection{Defined Relation of Machine Components in a Form of Relation Matrix}

To define the relation between each machine component and its adjacent components [6-7], CAD software is a main tool to check this relation with formula (Equation 1): Relation $=1$ means that considered component surface is contacted with its adjacent components and Relation = 0 means that considered component surface is not contacted with its adjacent components [8-10].

$$
\begin{aligned}
& 0\left(\mathrm{i}=\mathrm{j} \text { or } \mathrm{a}_{\mathrm{j}} \succ \mathrm{a}_{\mathrm{i}}\right) \\
& \mathrm{a}_{\mathrm{ij}}={ }_{1\left(\mathrm{a}_{\mathrm{j}} \rightarrow \mathrm{a}_{\mathrm{i}}\right)}
\end{aligned}
$$
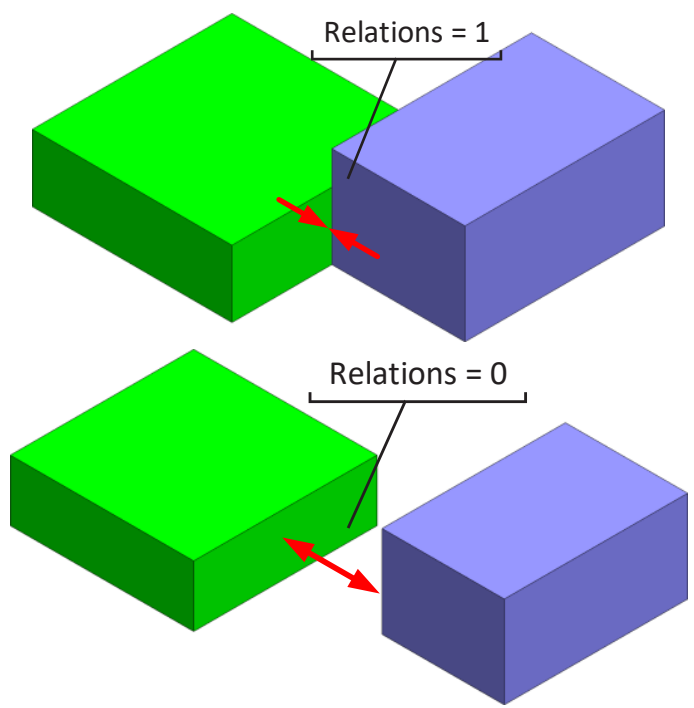

Fig. 3 Show how to define relation value.

With CAD software, this machine can be exploded into 75 components and relation of each compont and its adjacent components are defined and shown in Fig. 4 in form of a design matrix.

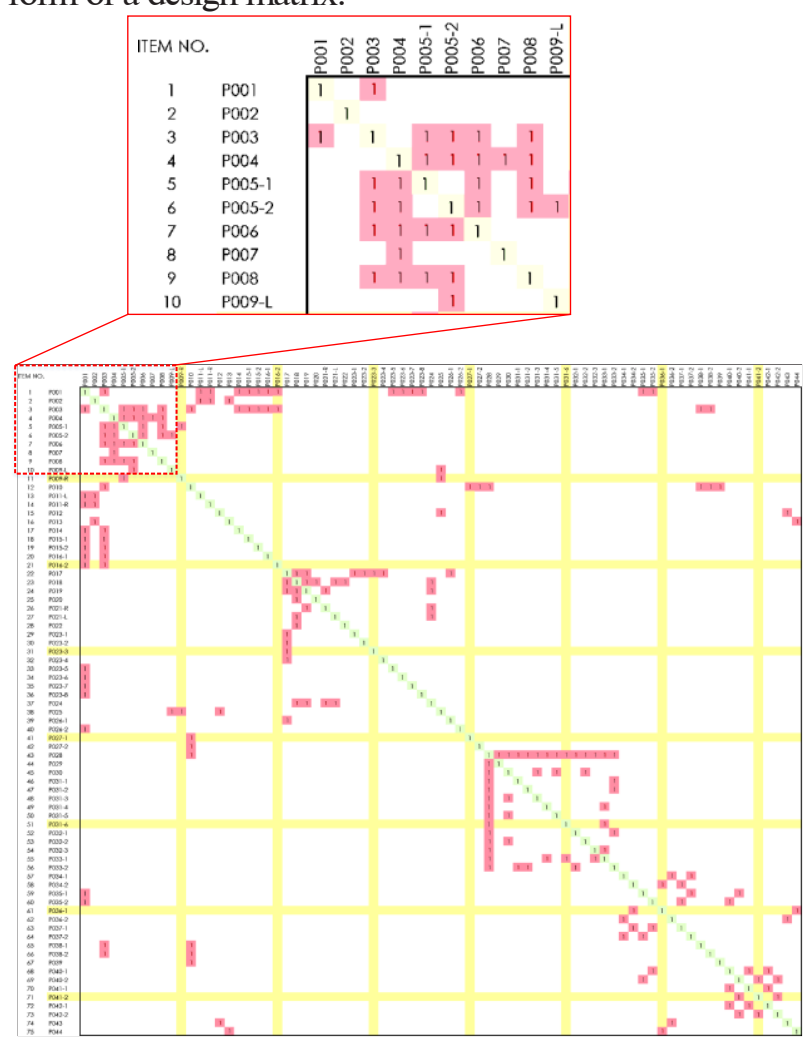

Fig. 4. Relation matrix of soil mixing machine components.

\subsection{Create a Distance matrix with Jaccard Method}

Jaccard index formula (Equation 2 and 3) is applied to a relation matrix [9] in Fig. 4. Finally, a relation matrix shall be transferred into a distance matrix as shown in Fig. 5.

$$
\begin{aligned}
\operatorname{Jsim}(A, B) & =\frac{A \cap B}{A \cup B}=\frac{a}{a+b+c} \\
\operatorname{Jdist}(A, B) & =1-J \operatorname{sim}(A, B)
\end{aligned}
$$

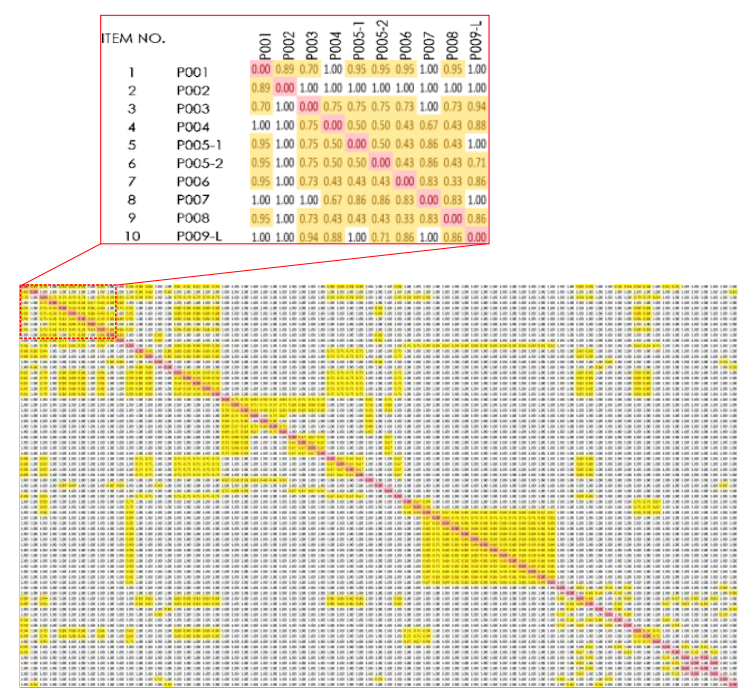

Fig. 5. A distance matrix of soil mixing machine base on Jaccard method. 


\subsection{Create a Dendrogram with Complete Linkage Formula}

In this step, complete linkage formula (Equation 4) is applied to a distance matrix [8] in Fig. 5 to create a dendrogram of this machine as shown in Fig. 6.

$\mathrm{D}\left(\left(\mathrm{C}_{\mathrm{i}} \cup \mathrm{C}_{\mathrm{j}}\right), \mathrm{C}_{\mathrm{k}}\right)=\max _{\mathrm{x} \notin \mathrm{c}_{\mathrm{i}}, \mathrm{y \notin c_{j }}}\left\{\mathrm{d}\left(\mathrm{x}_{\mathrm{i}}, \mathrm{x}_{\mathrm{k}}\right), \mathrm{d}\left(\mathrm{x}_{\mathrm{j}}, \mathrm{x}_{\mathrm{k}}\right)\right\}$

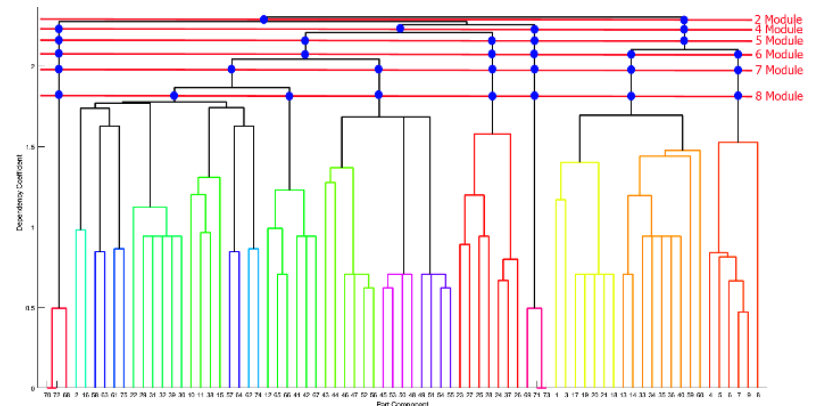

Fig. 6. A dendrogram of soil mixing machine.

Fig. 6 shows that the numbers of cluster are depend on the value of dependency coefficient. In this study, six dependency coefficient values from 2.4 to 1.7 are defined so that 1) There are 2 modules for the dependency coefficient $=2.4,2$ ) There are 4 modules for the dependency coefficient $=2.35,3$ ) There are 5 modules for the dependency coefficient $=2.3,4$ ) There are 6 modules for the dependency coefficient $=2.2,5$ ) There are 7 modules for the dependency coefficient $=1.9$ and 6) There are 8 modules for the dependency coefficient $=1.7$

\subsection{Select the Appropriate Dependency coefficient with Repeating Method}

Among six dependency coefficient values, the most appropriate value for this machine is selected with repeating method Fig. 7. And Fig. 8. shows that.

\begin{tabular}{|c|c|c|c|c|c|c|c|c|c|}
\hline & \multirow{2}{*}{\multicolumn{9}{|c|}{ 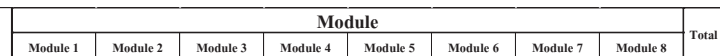 }} \\
\hline & & & & & & & & & \\
\hline $\begin{array}{l}\text { Levect } \\
\text { a.2.1) }\end{array}$ & 6 & 20 & & & & & & & \\
\hline & & 22 & & & & & & & \\
\hline $\mid \begin{array}{l}\text { Lever } 2 \\
0.235\end{array}$ & (1) & 6. & 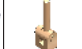 & 3 & & & & & \\
\hline 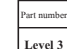 & & & 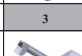 & & $\rightarrow$ & & & & \\
\hline \begin{tabular}{|l}
$(2.3)$ \\
\end{tabular} & 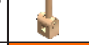 & 6 & 4 & a & 13 & & & & \\
\hline 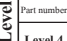 & 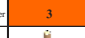 & a & & & 22 & & & & \\
\hline (2.2.) & 6 & 6 & 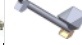 & 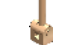 & 3 & 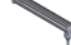 & & & 7 \\
\hline 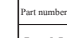 & & 40 & & & & & & & \\
\hline $\begin{array}{l}\text { Lacers } \\
\text { (1.9) }\end{array}$ & 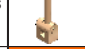 & 3 & 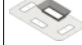 & 4 & 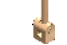 & 3 & $\gamma$ & & \\
\hline Level6 & & 26 & 14 & 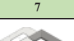 & & & $\infty$ & & \\
\hline & 8 & & & & & $\pi$ & 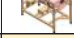 & & \\
\hline
\end{tabular}

Fig. 7 Repeating table of modules of soil mixing machine.

Fig.7. Show the repeating of module soil mixing machine by searching a module that has been repeating most frequently in the repeating table.

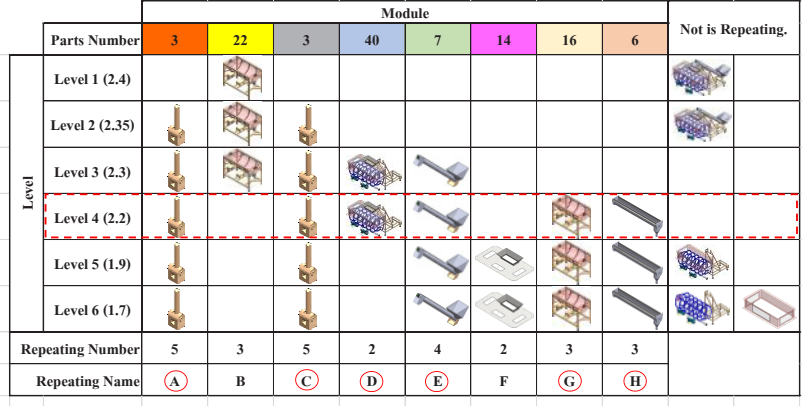

Fig. 8. Select of Repeating Module.

Fig. 8. Shows the selection with repeating of module from Repeating Table in Fig. 7., indicate clearly the module of soil mixing machine as shown in Fig. 9.

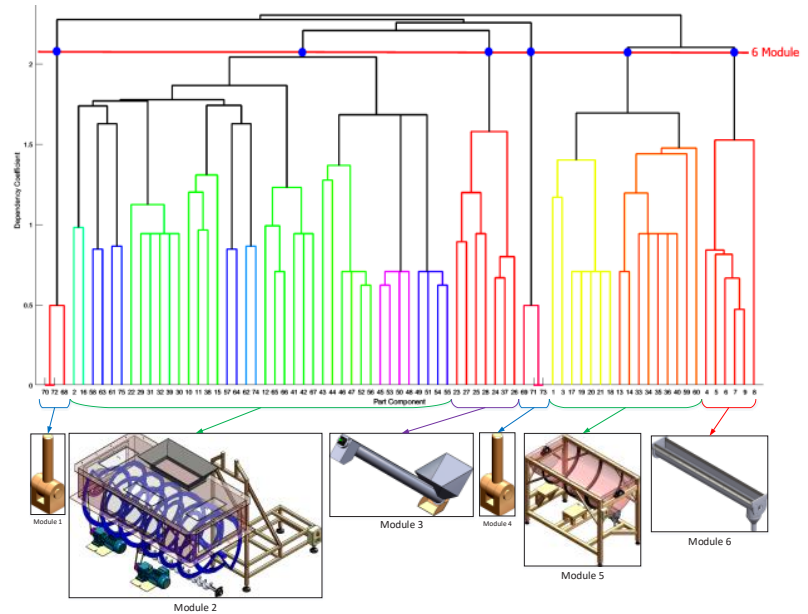

Fig. 9 The dendrogram has shown module.

From the case studies in this research can explain the clustered components of soil mixing machine, as in the Fig. 10.

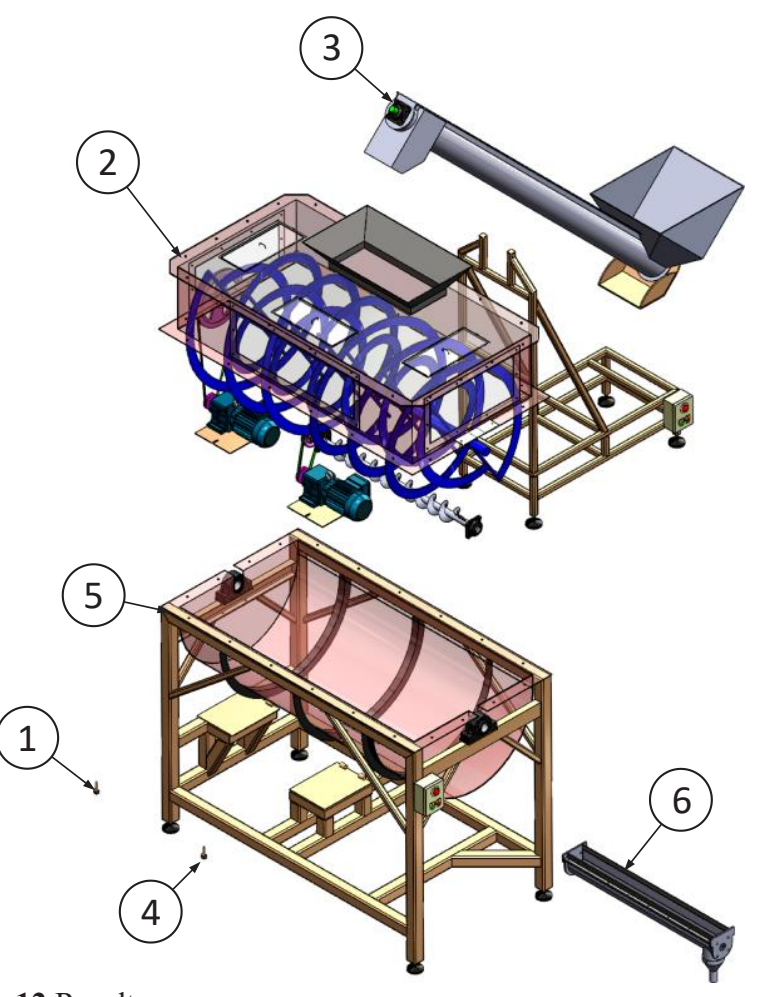

Fig. 12 Result. 


\section{Conclusion}

In this paper, we have studied how to cluster components for the module of the soil mixing machine. By defining the relationships between each component and repeating method by creating a module of the machine.

The approach is applied to the clustering with DSM and repeating method of modular design of soil mixing machine are results so the value dependent coefficient $=$ 2.2 and modules of machine $=6$ Modules.

The cluster with 6 modules is considered to be the most proper cluster for this soil mixing machine by applying the repeating method to analyze six clusters.

\section{References}

1. Tyson R. Browing, Applying the Design Structure Matrix to System Decomposition and Integration Problems: A Review and New Directions, IEEE Transactions on Engineering Management, Vol 48, No.3, August 2001

2. Xuejian Gong, Titao Liu, Roger, J. Jiao, VarietyDriven Assembly Layout Design by Design Structure Matrix Clustering Analysis, CIRP Conference on Manufacturing, 63 (2017)

3. Tarek ALGeddawy, A DSM Cladistics module for product family architecture design, CIRP Design Conference, 21 (2014)

4. Vladimir Maslak, Dmitry Boytsov, Modular design of subway facilities, International scientific conference "Underground Urderanisation as a Perequisite for Sustainable Development", 165 (2016) 782-787

5. Simon Li, Mehrnaz Mirhosseini, A matrix-based modularization apporting secure collaboration in parametric design, Computers in Industry, 63 (2012)

6. Xiaoguang Deng, Greg Huet, Suo Tan, Clement Fortin, Product decomposition using design structure matrix for intellectual property protection in supply chain outsourcing, Computers in Industry, 63 (2012)

7. Robert Helmer, Ali Yassine and Christoph Meier, Systematic module and interface definition using component design structure matrix, Journal of Engineering Design, Vol. 21, No. 6, December 2010

8. Brian Everitt, Sabine Landau, Morven Leese, Daniel Stahl, Cluster Analysis (John Wiley \& Sone, Ltd, 2011)

9. Guojun Gan, Chaoqun Ma, Jianhong $\mathrm{Wu}$, Data Clustering Thery, Algorithms and Applications, (SIAM, 2007)

10. Steven D. Eppinger and Trson R. Browning, Design Structure Matrix Methods and Application, (MIT Press, 2012) 